\title{
Gold Nanorings Encapsulated in PNIPAM Nanoparticles
}

\author{
Sofía Alejandra Tovar-Cabrera ${ }^{1}$, Armando Lucero-Acuña $^{2}$ and Reynaldo Esquivel ${ }^{1 *}$ \\ 1. Nanotechnology Graduate Program, Department of Physics, University of Sonora, Mexico. \\ 2. Department of Chemical and Metallurgical Engineering, University of Sonora, Hermosillo, Mexico. \\ * Corresponding author: resquivelgo@conacyt.mx
}

The areas where the synthesis and application of nanostructured materials have had an impact are diverse. The medical applications one of the most important has been where research has sought to provide a better quality of life in the patient. Nanoparticles of biocompatible materials such as some polymers and noble metals are studied to monitor, diagnose or release drugs in a controlled manner. In response, information has been obtained from the advantages of the use of composite materials [1-2]. The nanocomposites that act in a synergistic way allow taking advantage of the virtues of its different components. The importance of the use of metallic nanoparticles within these nanocomposites is not only the biocompatibility of noble metals such as gold, silver or titanium but also in the use of their optical properties as is the case of gold or bactericides like silver [3]. These nanoparticles can be synthesized with different morphology (hollow particles, solids, bars, cubes, etc.) according to the properties you want to obtain [4]. On the other hand, thermosensitive polymers have become famous for their ability to modify their properties by making changes in the environment in which they are located. Example of this is poly (isopropylacrylamide) (PNIPAM) which presents changes in its structure by modifying the temperature of its environment [5-6].

In this work gold nanoring's (AuNr) were prepared by galvanic replacement [6] of silver nanoparticles (AgNp) when the AgNp which were previously embedded in nanoparticles of PNIPAM by the difference in size. PNIPAM nanoparticles were obtained by polymerization of free radicals from NIPAM [4]. The AgNp and PNp was prepared for separate. The preparation of AgNp are synthesized after the overnight reduction of silver nitrate $\left(\mathrm{AgNO}_{3}\right)$ by sodium borohydride $\left(\mathrm{NaBH}_{4}\right)$ in the presence of sodium citrate at $80^{\circ} \mathrm{C}$ [2]. The PNp nanoparticles synthesis was prepared by isopropylacrylamide (NIPAM) and N,N'-methylenebisacrylamide (BIS) under magnetic stirring for 18 hours. Temperature was then raised to $70^{\circ} \mathrm{C}$ and sodium dodecyl sulfate was added. A nitrogen atmosphere was maintained for 15 minutes, a $60 \mathrm{mM}$ ammonium persulfate (APS) solution was added, and the solution was maintained under agitation for 45 minutes. The AgNp-PNp was prepared under magnetic stirring for 10 minutes at room temperature $\left(25^{\circ} \mathrm{C}\right)$ to promote that $\mathrm{AgNp}$ were embedded in the PNp particles by difference in size, $\sim 60 \mathrm{~nm}$ and $\sim 250 \mathrm{~nm}$ respectively. Finally, the nanocomposite AuNr-PnP was prepared in stirring at $60^{\circ} \mathrm{c}$ by galvanic replacement in the solution of AgNp-PNp nanoparticles used as the template by adding $\mathrm{HAuCl}_{4}$ concentrate to obtain $\mathrm{AuNr}$ encapsulated in $\mathrm{PNp}$.

Surface morphology of the nanoparticles was studied by scanning transmission electron microscopy (STEM) using a JEOL JSM-7800F. Samples were placed in a formvar carbon film. Figure 1 and Figure 2 show AuNr-PNp micrographs. The resulting sizes ranged from 50 to $80 \mathrm{~nm}$. The chemical composition was corroborated by EDS Spectrum by Bruker Nano (Figure 3).

\section{References:}

[1] NJ Halas et al., Chem. Res. 41 (2008), p. 1842. 
[2] J Park et al., El Sevier, (2015), p.77.

[3] RC Carrillo-Torres et al., RSC Advances, 6 (2016), p. 41304.

[4] Y Sun et al., Adv. Mater. (2003), p. 641.

[5] R Esquivel et al., e-Polymers (2017), p. 163.

[6] SR Sershen et al., Appl. Phys. B Lasers Opt. 73 (2001), p. 379.

[7] BG Prevo et al., Small 4 (2008), p. 1183.

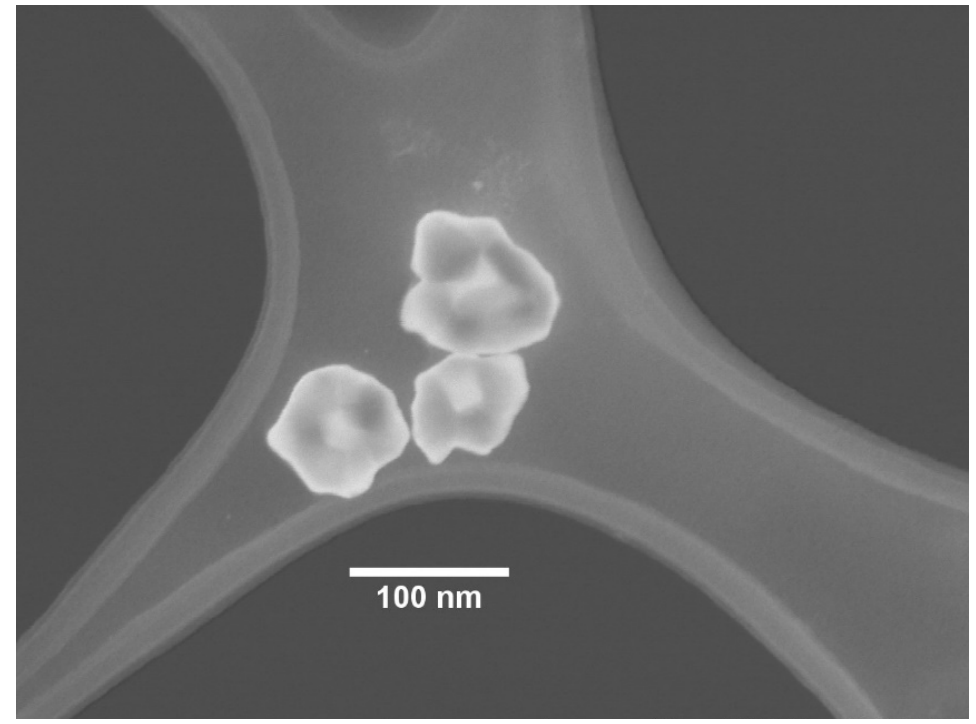

Figure 1. STEM micrograph of AuNr-PNp.

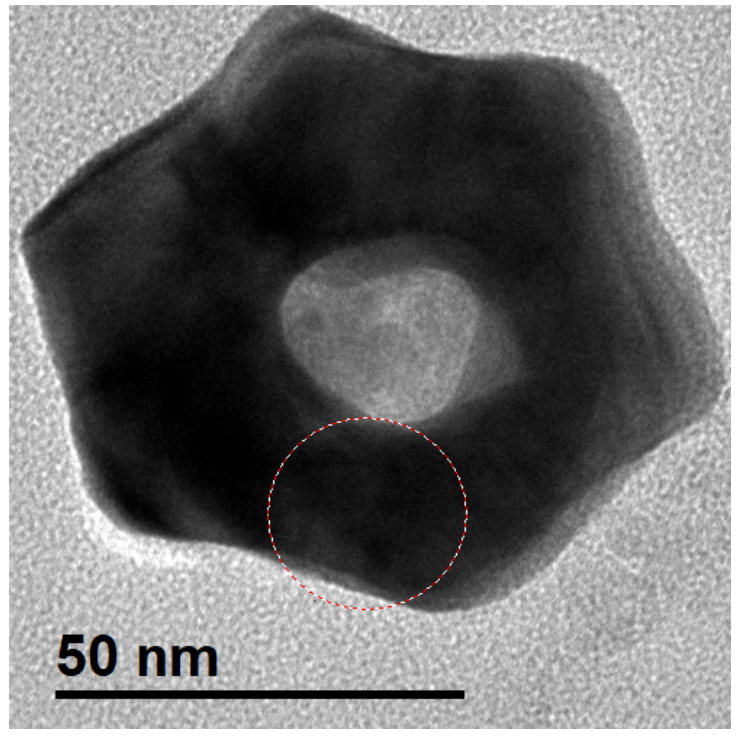

Figure 2. TEM micrograph of $\mathrm{AuNr}-$ PNp.
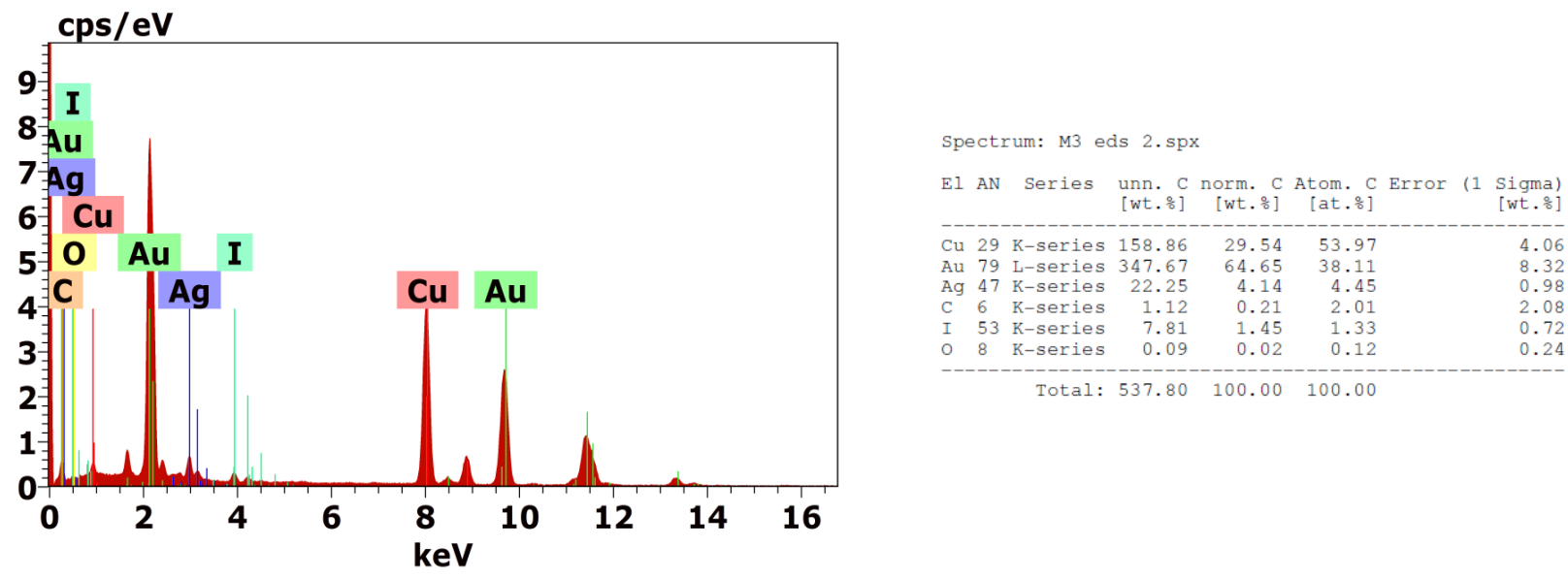

Figure 3. EDS results of AuNr-PNp. 